\title{
The prevalence of anabolic androgenic steroid use amongst athletes in Riyadh (Saudi Arabia)
}

\author{
Mosleh Jabari ${ }^{1}$, Hassan Al-shehri ${ }^{1}$, Abdullah Al-faris ${ }^{2}$, Mohammed Al-sayed ${ }^{2}$, Fahd Algaeed ${ }^{3}$, Nasser Al-sobaie ${ }^{3}$, \\ Fawaz Al-saleh ${ }^{3}$
}

${ }^{1}$ Department of Pediatrics, College of Medicine, Al-Imam Muhammad Ibn Saud Islamic University, Riyadh, Saudi Arabia

${ }^{2}$ Department of Pediatrics, Security Forces Hospital, Riyadh, Saudi Arabia

${ }^{3}$ Medical Students, College of Medicine, Al-Imam Muhammad Ibn Saud Islamic University, Riyadh, Saudi Arabia

\section{Type of article: Original}

\begin{abstract}
Objective: The aim of this study was to determine the prevalence of anabolic androgenic steroid (AAS) use among athletes and examine the extent of their knowledge on the effects of AAS in Riyadh, Saudi Arabia.

Methods: This cross-sectional study was conducted at gyms in Riyadh, Saudi Arabia, during 2015. In total 600 athletes from three gyms participated in the study. The study included Saudi and non-Saudi athletes chosen by the simple random sampling method. A self-reported questionnaire was used for data collection. The questionnaire was designed to study the prevalence and assess the knowledge of athletes regarding AAS use. Frequency and percentage distributions were used to describe the data. Comparison between the subgroups was made with a chisquare test.

Results: The percentage of AAS users was 30.5\%. The age of AAS users ranged from 15 to 49 years with the majority (52.5\%) belonging to age group of $25-29$ years. Approximately $20 \%$ of the users admitted using AAS due to body dysmorphia as their best motivational factor; in addition, they also believed that there are no side effects of the use. Among the nonusers, $40 \%$ had appropriate knowledge, while all the AAS-users had inadequate knowledge about the adverse effects of AAS. Moreover, $77 \%$ of the users would recommend AAS to their friends but none from the nonusers. A significant difference in age distribution $(\mathrm{df}=5, \mathrm{p}<0.001)$ and knowledge $(\mathrm{df}=4$, $\mathrm{p}<0.001$ ) between users and nonusers was observed.

Conclusion: Most athletes were ignorant of the harmful side effects of the drug but still continued to use and promote it to other athletes. These athletes should intensify their knowledge and awareness regarding the use of AAS and its effects on the body.
\end{abstract}

Keywords: Anabolic androgenic steroid, Body dysmorphia, Athletes, Motivation

\section{Introduction}

Anabolic androgenic steroids (AAS) are testosterone-like synthetic hormones, which have anabolic and androgenic properties (1). The anabolic effect is more prominent and causes nitrogen retention, increased muscle mass and bone density, decreased body fat, stimulation of erythropoiesis, and cardiac hypertrophy and hepatomegaly (2). Moreover, AAS has a harmful effect on the pituitary-gonadal axis (3). The androgenic properties are relatively weaker and cause the development of male sexual features and other collateral effects (4). Clinically, AAS are prescribed to treat conditions such as HIV-related muscle wasting, muscle dystrophies, severe burn injuries, bone marrow failure, hereditary angioedema, and growth retardation in children (5-9). Nevertheless, AAS use is associated with various dose-related side effects. Supra-physiological doses of AASs can lead to serious physical and psychological complications, such as hypertension, atherosclerosis, myocardial infarction, cardiac hypertrophy, abnormal blood clotting, hepatotoxicity and hepatic tumors, tendon damage, reduced libido, and psychiatric/behavioral symptoms such as aggressiveness and irritability $(1,10,14)$. Furthermore, AAS causes hypofertility and gynecomastia in men

\section{Corresponding author:}

Assistant Professor Dr. Hassan Al-Shehri, Department of Pediatrics, College of Medicine, Al-Imam Muhammad Ibn Saud Islamic University, Riyadh, Saudi Arabia , E-mail: dr.h.alshehri@hotmail.com Received: August 08, 2016, Accepted: October 10, 2016, Published: December 2016 iThenticate screening: October 10, 2016, English editing: November 26, 2016, Quality control: December 06, 2016 (C) 2016 The Authors. This is an open access article under the terms of the Creative Commons Attribution-NonCommercialNoDerivs License, which permits use and distribution in any medium, provided the original work is properly cited, the use is non-commercial and no modifications or adaptations are made. 
(15). Since 1950, AAS has been used by athletes and recreational bodybuilders worldwide (10). The motivation behind AAS use by athletes is to enhance strength, the size of the muscles and overall performance in shorter duration rather than just proper diet and physical training alone. Athletes using AAS are mostly unaware of the adverse side effects of the drug, which might affect their health. A plethora of surveys have been conducted to assess the prevalence, knowledge, and motivation for AAS use by athletes and collegiate and school students, which provides an overview of the medical burden that society is going to bear (16-20). However, such studies on the population of Saudi Arabia are lacking. Therefore, we aim to investigate the prevalence and motivation of AAS use, knowledge of its adverse side effects amongst the fitness center users in Riyadh.

\section{Material and Methods}

\subsection{Research design and participants}

This cross-sectional survey was conducted on athletes visiting gymnasiums of Riyadh, Kingdom of Saudi Arabia, during 2015. In total 600 athletes participated in the study, including Saudi and non-Saudi athletes chosen by the simple random sampling method. The age of the athletes was within the range from 15-49 years and divided into six groups: 15-19 years, 20-24 years, 25-30 years, 30-34 years, 40-44 years, and 45-49 years. Voluntary participation was followed, and all the participants signed a consent form before participating in the study. This study was approved by the Ethics Committee in college of medicine at Al-Imam Muhammad Ibn Saud Islamic University, Kingdom of Saudi Arabia.

\subsection{Questionnaire}

Self-reported questionnaires were used for data collection. The questionnaire's validity and reliability were confirmed by pilot study. The questionnaire was designed to study the prevalence and assess the knowledge of athletes regarding AAS use. The survey consisted of questions on age, marital status, usage of AAS, the motivation behind AAS use and knowledge on the side effects of AAS. A site instructor emphasized the need for truthful and honest answers from participants. The responses to the questionnaire were kept confidential.

\subsection{Statistical analysis}

Data analysis was performed using statistical software SPSS (version 21). Frequency and percentage distributions were calculated. Comparison between subgroups was made with chi-square tests considering confidence interval of $95 \%$. Basic data were regarded as normally distributed. A p-value less than 0.05 was considered statistically significant.

\section{Results}

In this study, a total of 600 athletes visiting gymnasium participated in this study. All of them were male. The response rate of the survey was $100 \%$. The age of the athletes ranged from 15-49 years. The percentage of athletes who have used AAS ("AAS-users") in this study was 30.5\%. The age distribution of the responders was divided into users and nonusers. A significant difference in age distribution between users and nonusers was observed $(\chi 2=$ $488.638, \mathrm{df}=5, \mathrm{p}<0.001)$. Although the age of AAS users ranged from 15 to 49 years, a majority $(52.5 \%)$ of them belonged to age group 25-29 years, followed by the age groups 15-19 (21.9\%) and 30-34 (20.8\%) (Figure 1). Even though the number of athletes in the age group $>40$ years were less, all of them used AAS. No difference was observed between the AAS users and nonusers regarding the motivation for AAS use $\left(\chi^{2}=2.474, \mathrm{df}=5, \mathrm{p}=0.780\right)$ (Table 1). Most responders had no drive or motivation for AAS usage (users $(69.4 \%)$ and nonusers $(70 \%)$ ). The predominant reason for AAS usage among the users $(\sim 20 \%)$ and nonusers $(\sim 20 \%)$ was for attaining good physique with the belief that no side effects were present. Approximately $2 \%-3 \%$ of the users and nonusers opined that AAS use maintains body shape without having any side effects, while $5 \%-6 \%$ of them believed that AAS only affects body shape and has no effects. A minority of the responders ( $\sim 1 \%)$ opined that AAS use has no effects except for long-term usage (Table 1). On examining the knowledge on potential adverse effects of AAS, we found that $40 \%$ of the nonusers belonging to age group of 20-24 years only had appropriate knowledge on the negative effects of AAS use (Table 1). Surprisingly, all the AAS users had inadequate knowledge on the harmful effects of AAS. A considerable difference between users and nonusers on the knowledge of AAS side effects was observed $\left(\chi^{2}=\right.$ $477.501, \mathrm{df}=4, \mathrm{p}<0.001)$. Further, we also assessed the relationship between duration of AAS use and knowledge of adverse effects of AAS use. A remarkable difference was observed between the groups $(\chi 2=134.286$, df $=24$, $\mathrm{p}<0.001$ ) (Table 1). Approximately $69.7 \%$ of the athletes have no knowledge about their duration of AAS use. Athletes who have been using AAS up to 1 year have either complete knowledge or partial knowledge of the adverse effects of AAS. Interestingly, athletes using AAS for a longer duration had minimal knowledge on the adverse effects of AAS. All of the nonusers, irrespective of their knowledge on adverse effects of AAS and a 
fraction of users (28\%) who belonged to age group 15-19 years, do not want to recommend AAS to their friends (Table 1). However, $77 \%$ of the users, who are partially aware of detrimental effects of AAS use, would like to recommend their friends to use AAS. A significant difference between users and nonusers was observed $(\chi 2=419.994, \mathrm{df}=1, \mathrm{p}<0.001)$.

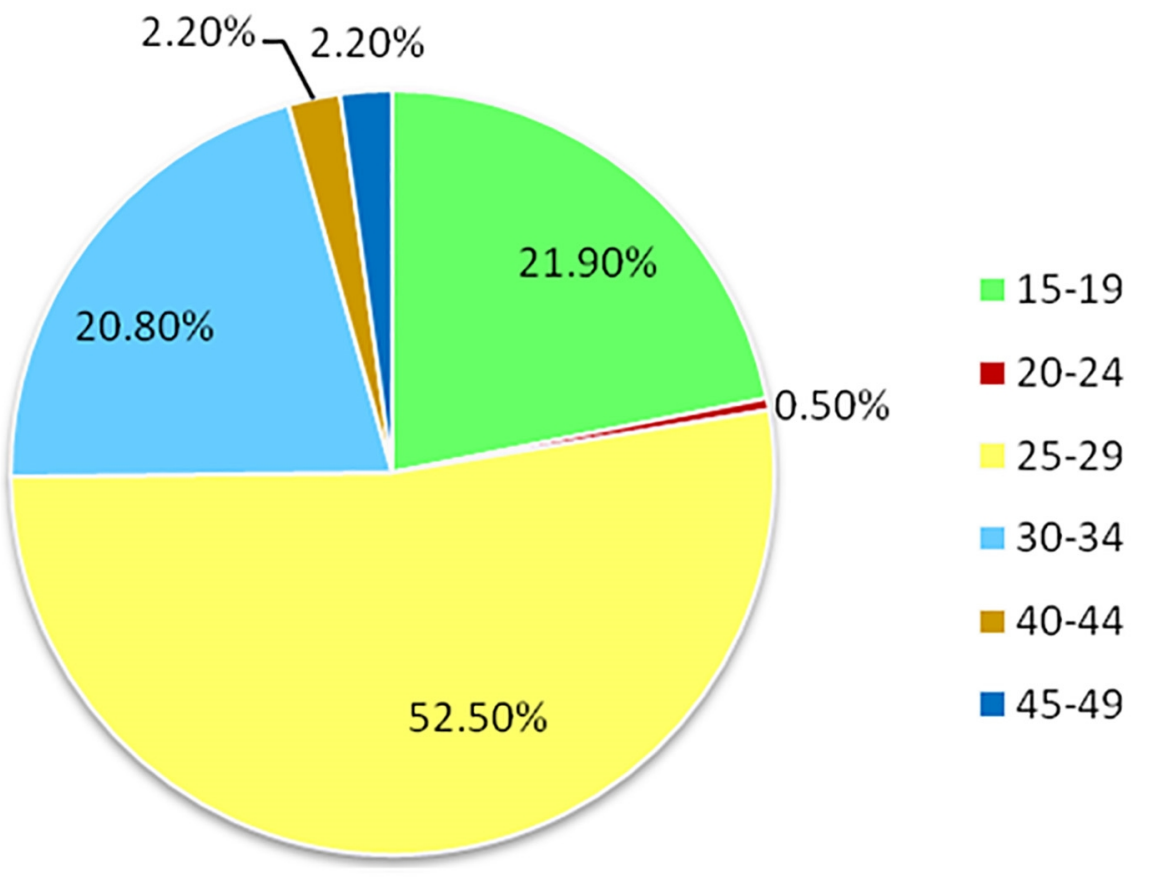

Figure 1. Age distribution of AAS users

Table 1. Chi-square analysis

\begin{tabular}{|c|c|c|c|c|}
\hline \multicolumn{2}{|l|}{ Variable } & $\begin{array}{l}\text { AAS } \\
\text { users }\end{array}$ & $\begin{array}{l}\text { Non- } \\
\text { users }\end{array}$ & $\begin{array}{l}\text { Significance } \\
\text { level }\end{array}$ \\
\hline \multirow[t]{6}{*}{ Motivation } & $\begin{array}{l}\text { Body shape and believing no side } \\
\text { effects }\end{array}$ & $20.2 \%$ & $20.1 \%$ & \multirow[t]{6}{*}{$p=0.780$} \\
\hline & Body shape and no effects & $3.3 \%$ & $2.4 \%$ & \\
\hline & Body shape & $6 \%$ & $5 \%$ & \\
\hline & No effects at all & $0 \%$ & $1 \%$ & \\
\hline & No effect except for long-term use & $1.1 \%$ & $1.4 \%$ & \\
\hline & No answer & $69.4 \%$ & $70 \%$ & \\
\hline \multirow{5}{*}{$\begin{array}{l}\text { Harmful effect } \\
\text { knowledge }\end{array}$} & Complete knowledge & $0 \%$ & $40 \%$ & \multirow[t]{5}{*}{$p<0.001$} \\
\hline & Liver damage & $0 \%$ & $23.5 \%$ & \\
\hline & Hormonal disorder & $0 \%$ & $27.3 \%$ & \\
\hline & Reproductive disorder & $44.8 \%$ & $9.1 \%$ & \\
\hline & Psychiatric problem & $55.2 \%$ & $0 \%$ & \\
\hline \multirow[t]{2}{*}{ Recommending friends } & Yes & $77 \%$ & $0 \%$ & \multirow[t]{2}{*}{$p<0.001$} \\
\hline & No & $23 \%$ & $100 \%$ & \\
\hline
\end{tabular}

\section{Discussion}

This study investigated the prevalence of AAS use, assessed the motivation, information on adverse effects, and recommending friends for AAS usage among athletes in Riyadh. The frequency of AAS users was $30.5 \%$ in this study, which was higher than in other Arabic states and Muslim countries. In Kuwait and UAE, the AAS users were reported to be $22.7 \%$ and $22 \%$, respectively $(17,19)$. The prevalence of AAS use amongst Iranian and Jordanian gym attendees was approximately $13 \%$ and $26 \%$, respectively $(16,20)$. Nevertheless, the frequency of AAS users was less when compared with that of Western countries such as United Kingdom (69.9\%) and United States (79.6\%) $(21,22)$. In this study, a wide age range was noted among athletes abusing AAS (15 to 49 years), with the majority 
(52.5\%) being in the age group of $25-29$ years. Note that $21.9 \%$ of the users were in the age group of $15-19$ years while only $0.5 \%$ of the athletes, belonging to the age group of 20-24 years, responded as users. Similarly, a majority $(\sim 70 \%)$ of users and nonusers had not mentioned their motivation for AAS use. These discrepancies are likely due to the validity of the self-report drug abuse where abusers of these drugs feel that their behavior is disapproved of, and so they might not disclose their abuse (23). The main reason for increasing AAS abuse is media where celebrities with good physiques become ideal for the general population (24). Also in this study, the reason behind AAS use was to attain an ideal body shape. Typically, adolescents and young population show more concern for attaining an ideal body shape. In the present study, in addition to younger age groups, middle-aged and older athletes have mentioned achieving body shape as their drive for AAS use, indicating a strong effect of media. The absence of complete knowledge about the detrimental effects of AAS usage among the AAS users has been reported (20). In accordance, all the AAS users in this study had inadequate knowledge about the adverse effects of AAS usage. Among nonusers, $40 \%$ had appropriate knowledge regarding the potential adverse effect of AAS use, which supports the notion that spreading awareness about the side effects of AAS may be the most effective strategy for limiting their abuse. Moreover, due to lack of proper knowledge, most AAS users agreed to advise their friends to use AAS. AAS users often have at least one friend or companion who uses or has used AASs (10). Thus, athletes should intensify their knowledge and awareness regarding the use of AAS and their effects on the body.

\section{Conclusions}

Based on our results, the percentage of AAS users here in Saudi Arabia is high considering that the anabolic steroid is illegal. Our first recommendation is to educate the present and future athletes in our community about the harmful effects of this drug. According to the users, they are using it for aesthetic purposes to improve their physical image. Unfortunately, they do not have enough knowledge about the adverse effects of the excessive use of this drug. Second, if the responsible authorities cannot monitor the underground market of this product, we recommend that they should legalize the use of this drug. This would help us to monitor the number of users as well as control the use of this drug. In this way, we can avoid the adverse effects before it happens.

\section{Acknowledgments:}

Nothing to acknowledge.

\section{Conflict of Interest:}

There is no conflict of interest to be declared.

\section{Authors' contributions:}

All authors contributed to this project and article equally. All authors read and approved the final manuscript.

\section{References:}

1) Hartgens F, Kuipers H. Effects of androgenic-anabolic steroids in athletes. Sports Med. 2004; 34(8): 51354. doi: 10.2165/00007256-200434080-00003. PMID: 15248788.

2) Hall RC, Hall RC. Abuse of supraphysiologic doses of anabolic steroids. South Med J. 2005; 98(5): 550-5. doi: 10.1097/01.SMJ.0000157531.04472.B2. PMID: 15954512.

3) Takahashi M, Tatsugi Y, Kohno T. Endocrinological and pathological effects of anabolic-androgenic steroid in male rats. Endocr J. 2004; 51(4): 425-34. doi: 10.1507/endocrj.51.425. PMID: 15351799.

4) Lang $T$, Streeper $T$, Cawthon P, Baldwin K, Taaffe DR, Harris TB. Sarcopenia: etiology, clinical consequences, intervention, and assessment. Osteoporos Int. 2010; 21(4): 543-9. doi: 10.1007/s00198-0091059-y. PMID: 19779761, PMCID: PMC2832869.

5) Gelfand JA, Sherins RJ, Alling DW, Frank MM. Treatment of hereditary angioedema with danazol: reversal of clinical and biochemical abnormalities. N Engl J Med. 1976; 295(26): 1444-8. doi: 10.1056/NEJM197612232952602. PMID: 792688.

6) Ammus SS. The role of androgens in the treatment of hematologic disorders. Adv Intern Med. 1989; 34: 191-208. PMID: 2644756.

7) Demling RH, Orgill DP. The anticatabolic and wound healing effects of the testosterone analog oxandrolone after severe burn injury. J Crit Care. 2000; 15(1): 12-7. doi: 10.1053/jcrc.2000.0150012. PMID: 10757193.

8) Joss EE, Mullis PE. Delayed puberty in boys. Current Therapy in Endocrinology and Metabolism. 1994; 5: 299-300. PMID: 7704738. 
9) Knopp WD, Wang TW, Bach Jr BR. Ergogenic drugs in sports. Clin Sports Med. 1997; 16(3): 375-92. doi: 10.1016/S0278-5919(05)70031-4.

10) Piacentino D, Kotzalidis GD, Del Casale A, Aromatario MR, Pomara C, Girardi P. Anabolic-androgenic Steroid use and Psychopathology in Athletes. A Systematic Review. Curr Neuropharmacol. 2015; 13(1): 101-21. doi: 10.2174/1570159X13666141210222725. PMID: 26074746, PMCID: PMC4462035.

11) Mewis C, Spyridopoulos I, Kühlkamp V, Seipel L. Manifestation of severe coronary heart disease after anabolic drug abuse. Clin Cardiol. 1996; 19(2): 153-5. doi: 10.1002/clc.4960190216. PMID: 8821428.

12) Socas L, Zumbado M, Pérez-Luzardo O, Ramos A, Pérez C, Hernández JR, et al. Hepatocellular adenomas associated with anabolic androgenic steroid abuse in bodybuilders: a report of two cases and a review of the literature. Br J Sports Med. 2005; 39(5): e27. doi: 10.1136/bjsm.2004.013599. PMID: 15849280, PMCID: PMC1725213.

13) Stimac D, Milić S, Dintinjana RD, Kovac D, Ristić S. Androgenic/anabolic steroid-induced toxic hepatitis. J Clin Gastroenterol. 2002; 35(4): 350-2. doi: 10.1097/00004836-200210000-00013. PMID: 12352300.

14) Winkler UH. Effects of androgens on haemostasis. Maturitas. 1996; 24(3): 147-55. doi: 10.1016/S03785122(96)82004-4. PMID: 8844628.

15) Dohle GR, Smit M, Weber RF. Androgens and male fertility. World J Urol. 2003; 21(5): 341-5. doi: 10.1007/s00345-003-0365-9. PMID: 14566423.

16) Tahtamouni LH, Mustafa NH, Alfaouri AA, Hassan IM, Abdalla MY, Yasin SR. Prevalence and risk factors for anabolic-androgenic steroid abuse among Jordanian collegiate students and athletes. European Journal of Public Health. 2008; 18(6): 661-5. doi: 10.1093/eurpub/ckn062. PMID: 18603598.

17) Alsaeed I, Alabkal JR. Usage and perceptions of anabolic-androgenic steroids among male fitness centre attendees in Kuwait--a cross-sectional study. Subst Abuse Treat Prev Policy. 2015; 10: 33 . doi: 10.1186/s13011-015-0030-5. PMID: 26296560, PMCID: PMC4546264.

18) Costa Abrahin OS, Félix Souza NS, Corrêa de Sousa E, Rodrigues Moreira JK, Cunha do Nascimento V. Prevalence of the use of anabolic androgenic steroids by physical education students and teachers who work in health clubs. Rev Bras Med Esporte. 2013; 19(1): 27-30. doi: 10.1590/S151786922013000100005.

19) Al-falasi O, Al-dahmani K, Al-eisaei K, Al-ameri S, Al-maskari F, Nagelkerke N, et al. Knowledge, attitude and practice of anabolic steroids use among gym users in Al-Ain District, United Arab Emirates. The Open Sports Medicine Journal. 2008: 75-81. doi: 10.2174/1874387000802010075.

20) Nojoomi M, Behravan V. Study of anabolic steroids and the awareness of their complications in bodybuilding athletes in Karaj (2003). RJMS. 2005; 11(44): 1057-63.

21) Perry PJ, Lund BC, Deninger MJ, Kutscher EC, Schneider J. Anabolic steroid use in weightlifters and bodybuilders: an Internet survey of drug utilization. Clin J Sport Med. 2005; 15(5): 326-30. doi: 10.1097/01.jsm.0000180872.22426.bb. PMID: 16162991.

22) Baker JS, Graham MR, Davies B. Steroid and prescription medicine abuse in the health and fitness community: a regional study. Eur J Intern Med. 2006; 17(7): 479-84. doi: 10.1016/j.ejim.2006.04.010. PMID: 17098591.

23) Yesalis CE, Bahrke MS. Doping among adolescent athletes. Baillieres Best Pract Res Clin Endocrinol Metab. 2000; 14(1): 25-35. doi: 10.1053/beem.2000.0051.

24) Yesalis CE. Use of steroids for self-enhancement: an epidemiologic/societal perspective. AIDS Read. 2001; 11(3): 157-60. PMID: 17004353. 